\title{
Review
}

\section{An animal model of functional electrical stimulation: evidence that the central nervous system modulates the consequences of training}

\author{
MA $\operatorname{Hook}^{*, 1}$ and JW Grau ${ }^{1}$ \\ ${ }^{1}$ Department of Psychology, Texas A\&M University, College Station, TX, USA
}

\begin{abstract}
Study Design: Review of how spinal neurons can modulate the consequences of functional electrical stimulation (FES) in an animal model.

Methods: Spinal effects of FES are examined in male Sprague-Dawley rats transected at the second thoracic vertebra. The rats are exposed to FES training $24-48 \mathrm{~h}$ after surgery. Experimental manipulations of stimulation parameters, combined with physiological and pharmacological procedures, are used to examine the potential role of spinal neurons.

Results: The isolated spinal cord is inherently capable of learning the response-outcome relations imposed in FES training contingencies. Adaptive behavioral modifications are observed when an outcome (electrical stimulation) is contingent on a behavioral response. In contrast, a lack of correlation between the response and outcome in training produces a learning deficit in the spinal cord, rendering it incapable of adaptive learning for up to $48 \mathrm{~h}$. The $N$-methyl-D-aspartic acid receptor appears to mediate both the adaptive plasticity and loss of plasticity, seen in this spinal model.

Conclusion: The behavioral effects observed with FES therapies are not simply due to the direct (motor) consequences of stimulation elicited by the activation of efferent motor neurons and/or selected muscles. FES training has the capacity to shape inherent spinal circuits and to produce a long-lasting behavioral modification. Further understanding of the spinal mechanisms underlying adaptive behavioral modification will be integral for establishing functional neural connections in a regenerating spinal system.

Spinal Cord (2007) 45, 702-712; doi:10.1038/sj.sc.3102096; published online 14 August 2007
\end{abstract}

Keywords: rat; FES; spinal cord injury; instrumental conditioning; rehabilitation; neural plasticity

\section{Introduction}

Functional electrical stimulation (FES) is used to facilitate the performance of motor behaviors such as standing, locomotion, walking, reaching, and bowel and bladder function in the spinally injured. ${ }^{1}$ It involves the application of electrical currents to stimulate muscle or nerve groups through surface or implanted electrodes. For example, electrical stimulation of the common peroneal nerve elicits a flexion response that facilitates performance of the swing phase of the gait cycle, or more simply, bending of the knee. ${ }^{1}$ The level of current used in FES varies depending upon the action to be performed, with the ultimate aim being to initiate and shape behaviors after a spinal cord injury. Early success has fueled interest in the methodology and has led to increased clinical application. Treatment generally results in increased independence for the patient, and

*Correspondence: MA Hook, Department of Psychology, Texas A\&M University, College Station, TX 77843-4235, USA in some cases, facilitates motor performance even after FES training has stopped. ${ }^{2}$

The focus of most FES training paradigms has been on the direct (motor) consequences of stimulation elicited by the activation of efferent motor neurons and/or selected muscles. ${ }^{1}$ It is envisaged that through the appropriate placement and tuning of the stimulation, adaptive behavioral patterns can be regularly elicited and maintained. Stimulation, of course, also engages sensory fibers that relay signals to the spinal cord. This afferent input can, depending upon its nature and strength, activate spinal circuits that induce, modulate or even inhibit the performance of the target response. ${ }^{3}$ Surprisingly, little is known about how spinal circuitry impacts the consequences of FES. In many cases, the implicit assumption appears to be that surviving spinal circuits play little or no role. Here we discuss recent evidence that suggests that spinal neurons can foster adaptive behavior in an FES paradigm. Using an animal 
model, we show how electrical stimulation of the tibialis anterior muscle elicits a flexion withdrawal response that is modified with experience. Our data suggest that modifications in the withdrawal response are spinally mediated. We outline the circumstances under which adaptive learning occurs and present evidence that this learning depends on neurochemical systems implicated in other examples of neural plasticity.

\section{Learning within an FES paradigm}

Many FES paradigms incorporate a form of selfregulation, wherein the onset, duration and/or intensity of stimulation is coupled to its behavioral consequences. ${ }^{4}$ In psychology, it is well established that instituting a response-outcome relationship can bring about a neurally mediated change in behavior known as instrumental learning (see Grau et $a l^{3}$ ). The outcome refers to a stimulus that 'reinforces' the behavioral modification. In FES therapies, the key stimulus event is tied to the electrical stimulation used to initiate a response. From a behavioral perspective, this could lead to learning in two ways. One possibility is that the onset of the stimulus both initiates the response and reinforces an adaptive modification that reduces reexposure to

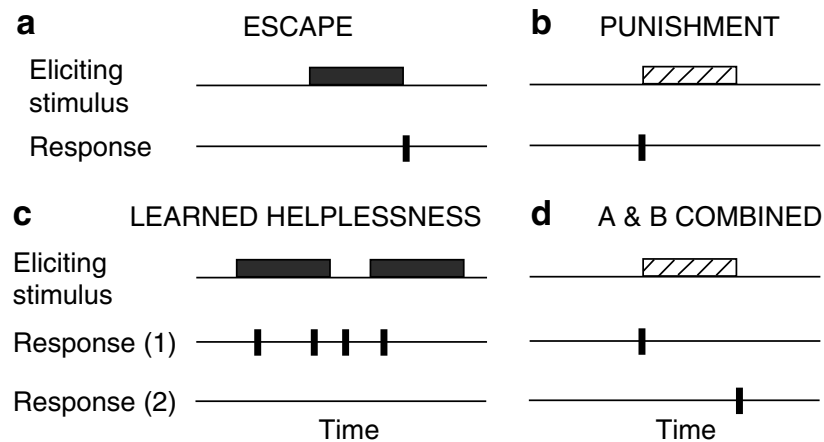

Figure 1 Response-outcome relationships in FES stimulation paradigms. Depicted are four models that represent the relationships between limb position (response) and electrical stimulation (outcome) in FES training paradigms. Interestingly, each model also characterizes conditions that support distinct forms of learning. (a) A behavioral response terminates exposure to electrical stimulation. In this case, learning can enhance the performance of the response and thereby minimize shock exposure. It is assumed that this type of escape learning is reinforced by the offset of shock (the critical outcome). (b) A response is followed by electrical stimulation. In this punishment paradigm, the subject learns a relationship between a particular response and the onset of shock (the outcome). As a result of learning, the subjects perform the response less frequently and receive less shock. (c) Electrical stimulation occurs independently of proprioceptive feedback. In the absence of a predictive relationship between a response and an outcome, the subject may exhibit a learned helplessness-like effect that inhibits subsequent learning. (d) Represents a theoretical combination between models (a) and (b). In this case, the onset and offset of electrical stimulation may be tied to distinct behavioral responses aversive stimulation, a form of learning known as punishment (Figure 1b). Alternatively, an adaptive response may be reinforced by the offset of shock, a behavioral effect known as escape learning (Figure 1a). There are also two additional possibilities. One occurs when both the onset and offset of the stimulus event are critical (punishment + escape; Figure 1d). The second arises when stimulation occurs in a manner that is uncorrelated with (independent of) the organism's behavior (Figure 1c). In uninjured animals, the absence of a response-outcome relation often induces a form of 'helplessness' that impairs learning and/or performance. ${ }^{5}$ It is as if the neural system recognizes that responding is futile and, as a result, gives up.

Our research was originally motivated by the question of whether spinal neurons could support some simple forms of learning (for a review see Grau et $a l^{6}$ ). Given this, we focused on detailing the environmental conditions that would support learning and the underlying neurochemical systems. Subsequently, we realized that our instrumental paradigm effectively modeled some FES therapies currently used for rehabilitation after a spinal cord injury, and that these FES procedures incorporated a response-outcome relation. For example, in FES systems designed to compensate for footdrop during stepping, a heel sensor is used to control the application of stimulation to the tibialis anterior muscle and common peroneal. ${ }^{7}$ In this case, stimulation is applied when the heel sensor is unweighted (the leg is lifted) and terminated when the step is completed. Other, more complex systems have been developed to enable coordinated movements, such as grasping and locomotion, and these too rely on response-outcome relations to ensure that the application of stimulation is closely coupled to its behavioral consequences. ${ }^{7}$ As most FES systems impose a response-outcome relationship, they can potentially support instrumental learning.

In the sections that follow, we describe our animal model of FES and present evidence that the behavioral consequences of training are modulated by spinal circuitry. We show that the key outcome is tied to the onset of the electrical stimulus and that presenting shock in a manner that is uncorrelated with behavior can have an adverse effect.

\section{An animal model of FES}

In our model, male Sprague-Dawley rats (Harlan, Houston, TX, USA) are transected at the second thoracic vertebra (for additional details see Grau et $a l^{3}$ ). Normally, FES training is conducted soon after surgery (24-48 h). However, this is not essential; rats transected soon after birth can learn in our paradigm when tested months later as adults. ${ }^{8}$ Training is conducted, whereas subjects are loosely restrained in Plexiglas tubes (Figure 2a). After the subject is secured, a stimulating electrode is placed in the tibialis anterior muscle. The circuit is completed using a wire that is inserted through the skin $17 \mathrm{~mm}$ below the first 

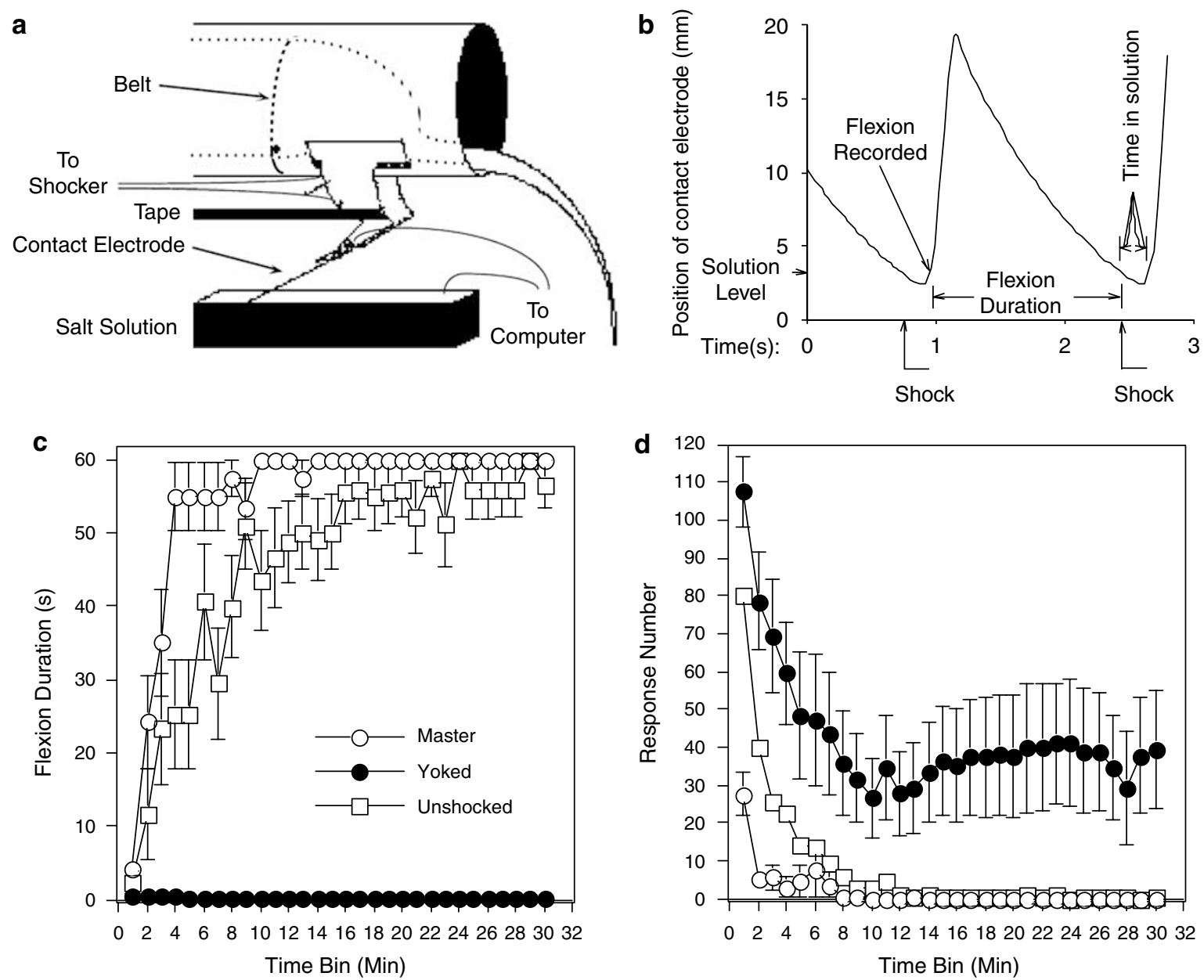

Figure 2 Instrumental learning in the spinal cord. (a) The apparatus used to study instrumental learning. Leg position is monitored using a contact electrode constructed from a $7 \mathrm{~cm}$ (length) $\times 0.7 \mathrm{~mm}$ (diameter) stainless-steel rod that is taped to the foot. When the leg is extended, the contact electrode contacts an underlying salt solution and completes an electrical circuit that is monitored by a computer. Completion of the circuit generates an electrical stimulus that is applied to the tibialis anterior muscle. This stimulation elicits a flexion response, lifting the tip of the contact electrode out of the salt solution and breaking the electrical circuit. (b) A computer measures the number of responses (times the contact electrode touches the salt solution) and the amount of time in solution. Our measure of learning is derived using the following formula: Flexion duration ${ }_{i}=\left(60-\right.$ Time in solution $\left._{i}\right) /$ (Flexion number ${ }_{i}+1$ ), where $i$ is the current training bin. (c) Using a master-yoke paradigm, we are able to directly compare the effects of response-contingent (controllable, master) and noncontingent (uncontrollable, yoked) FES training on behavior. In this paradigm, subjects are trained with controllable or uncontrollable stimulation paradigms and then are tested under common conditions (all subjects are exposed to response-contingent stimulation). Learning is indicated by an increase in flexion duration over time. Master rats reacquire the task more rapidly. Prior training with uncontrollable shock (yoked) disrupts learning for up to $48 \mathrm{~h}$. (d) Differences in flexion duration cannot be attributed to differences in the subject's capacities to make the flexion response. Yoked rats exhibited the highest rate of responding, despite their inability to learn. Adapted from Grau et al $l^{3}$

electrode. The intensity of the electrical stimulation is then adjusted to elicit an equivalent flexion force (eg, $0.4 \mathrm{~N}$ ) across subjects. Leg position is monitored by taping a contact electrode to the subject's paw. This electrode is insulated from the rat's foot and is positioned over a salt solution. When the leg is in a relaxed position, the contact electrode touches the underlying salt solution and completes a circuit that is monitored by a computer. When a shock is applied, muscle stimulation elicits a flexion response that raises the electrode and breaks the circuit. With this setup, we can vary the difficulty of the response requirement by simply raising the level of the salt solution; within limits, the further the contact electrode is submerged at the start of training, the longer it takes the subjects to learn. Learning in this paradigm is linked to an increase in flexion duration - as subjects learn, they exhibit a progressive increase in response duration that effectively minimizes exposure to shock.

Using this paradigm, spinally transected rats are tested with response-contingent (controllable) shock for $30 \mathrm{~min}$. When the computer detects a solution contact 
(the leg is down), a shock is applied (Figure 2b). Shock is terminated as soon as the contact electrode is lifted out of the solution. Under these conditions, electrical stimulation does not elicit a fixed response. Instead, subjects exhibit a progressive increase in response duration (Figure 2c) that reduces net shock exposure (Figure 2d). As subjects learn, they contact the underlying salt solution less often and receive fewer shock stimuli. In behavioral terms, the increase in response duration is accompanied by a decrease in response number.

We hypothesized that the increase in response duration depends on the response-outcome (leg position-electrical stimulation) relation. It is possible, however, that this relationship is irrelevant. Indeed, repeated stimulation, by itself, can sometimes produce a behavioral modification. For example, the motor effect of stimulation may summate over time, producing a lasting flexion response. Alternatively, the pain (nociceptive) signal might sensitize neurons within the spinal cord, a phenomenon known as central sensitization. ${ }^{9}$ This sensitization could, independent of any responseoutcome relation, amplify the behavioral output. To evaluate whether the response-outcome relation matters, we have used a master-yoke paradigm. In this paradigm, one group of rats (master) is exposed to response-contingent electrical stimulation. These subjects receive shock when their leg is extended and the shock is terminated when they flex the leg. A second group of rats (yoked) are shocked whenever their master partner extends its leg. In the yoked group, electrical stimulation is uncontrollable (Figure 1c). Both the master and yoked rats receive exactly the same amount of electrical stimulation, but only the master is exposed to a relationship between leg position and shock. If the change in flexion duration is due to exposure to shock alone, both master and yoked rats should exhibit an increase. This is not observed (Figure 2c). Rather, only the master rat exhibits an increase in flexion duration over time (Figure 2c). The yoked rat does exhibit a stimulation-induced withdrawal response each time that shock is applied (Figure 2d), but this behavioral response is not accompanied by an increase in response duration.

Additional evidence that the response-outcome relation is critical has been obtained by manipulating temporal contiguity. If learning depends on the response-outcome relation, then delaying the outcome should disrupt learning. We evaluated this possibility by delaying both the onset and offset of shock by 50,100 or $200 \mathrm{~ms} .{ }^{3}$ Subjects did not exhibit an increase in response duration when the outcome was delayed by $100 \mathrm{~ms}$ or more.

The change in response duration could be linked to either the onset of shock (punishment) or its offset (escape). To evaluate these alternatives, we delayed either shock onset or offset by $100 \mathrm{~ms}$. As can be seen in Figure 3, delaying shock offset had no effect. In contrast, when shock onset was delayed by $100 \mathrm{~ms}$, subjects did not exhibit an increase in response duration.

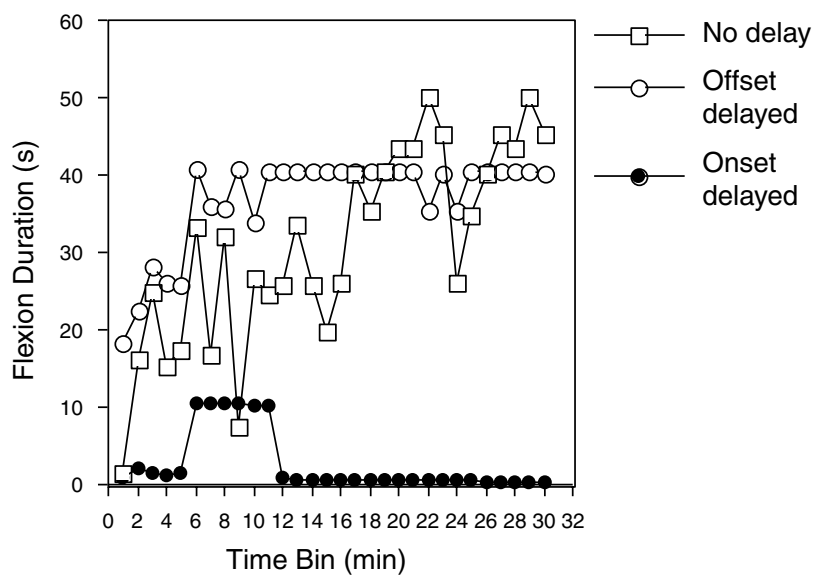

Figure 3 Spinal neurons learn through punishment. Delaying the onset of electrical stimulation by $100 \mathrm{~ms}$ prevents learning, whereas an equal delay in offset has no effect. Adapted from Grau et $a l^{3}$

In combination with the data from the master-yoke paradigm, these results imply that the increase in response duration depends on the response-outcome relation and that this learning is effectively reinforced by the onset of stimulation (punishment).

\section{FES training has a lasting effect}

The concept of learning is typically linked to a form of neural memory. In the above experiments, distinct response-outcome relations (master versus yoked) differentially affected our target response (flexion duration). What is not clear from these experiments is whether the training regimens have a lasting effect. This is an important issue because the regular application of shock could drive behavior to a particular end point (an increase in response duration) in a mechanical manner, and this could occur in the absence of learning. In such a system, there is no memory; the behavior observed is simply determined by the environmental contingency in effect. To evaluate whether instrumental training has a lasting effect in spinalized rats, subjects were given controllable (master) or uncontrollable (yoked) shock for $30 \mathrm{~min}$. A control group (unshocked) was treated the same except shock was withheld. At the end of training, we re-equated flexion force and contact electrode depth. Subjects were then tested under common conditions with $30 \mathrm{~min}$ of response-contingent shock. Master rats learned faster than the unshocked controls (a savings effect). In contrast, yoked rats failed to learn. Importantly, yoked rats did not fail to respond. These subjects exhibited a very high rate of responding for the entire $30 \mathrm{~min}$ of testing and, as a result, were repeatedly exposed to the response-outcome relation. Yet, they did not exhibit an increase in response duration. It appears that prior training with uncontrollable stimulation impairs subsequent instrumental learning, an effect reminiscent of learned helplessness. ${ }^{5}$ 
We were concerned that the deficit observed after uncontrollable shock reflected a form of sensory/motor impairment that was specific to the pretrained leg. To address this possibility, subjects were given uncontrollable shock and tested on the opposite (contralateral) leg. Again, they failed to learn. Indeed, even intermittent uncontrollable shock applied to the tail induced a learning deficit when subjects were later tested with response-contingent legshock. Just 6 min of intermittent tail shock produces a learning deficit that lasts 48 h. ${ }^{10}$ These observations suggest that exposure to uncontrollable electrical stimulation generally disables spinal learning.

We also examined whether training with controllable shock impacts test performance when subjects are tested on the contralateral leg. We found that pretrained rats exhibited superior learning and that this effect was especially evident when subjects were tested using a higher response criterion. ${ }^{11}$ Under these conditions, only pretrained rats exhibited an adaptive increase in response duration; nontrained rats failed to learn when a difficult (high) response criterion was imposed (Figure 4). This suggests that pretraining with controllable shock has a lasting effect that generally enables spinal learning.

Training with controllable shock also has a beneficial effect that inhibits the development of the learning deficit. ${ }^{12}$ Supporting this, rats given controllable shock before a session of uncontrollable shock do not exhibit a learning deficit when tested $24 \mathrm{~h}$ later. Conversely, the deficit can be reversed by combining instrumental training with a pharmacological treatment (i.t. naltrexone) that blocks the expression of the learning deficit. ${ }^{12}$

A simple explanation of these effects assumes that uncontrollable stimulation has an unconditioned effect on spinal plasticity that develops as a function of the duration and intensity of stimulation. Controllable stimulation appears to have a long-term benefit, in part, because it inhibits the development of the deficit. However, this benefit of training has its limits; if shock intensity is set to a high value, the adverse consequences of stimulation outweigh the benefits of instrumental control. Under these conditions, subjects will fail to learn even though a response-outcome relation is in effect. ${ }^{3}$ As we see below, the adverse consequences of uncontrollable stimulation have been linked to the activation of pain fibers. These considerations suggest that care must be taken when FES requires stimulus parameters that may engage pain fibers. If excessive nociceptive stimulation is applied, the adaptive plasticity of the spinal cord will be lost.

\section{Learning depends on spinal neurons}

We have shown that both controllable and uncontrollable stimulation can have a lasting effect in a model of FES. Do these effects depend on spinal neurons? One indication that spinal neurons are involved comes from data previously discussed. When subjects are trained with controllable shock applied to one hind leg, learning

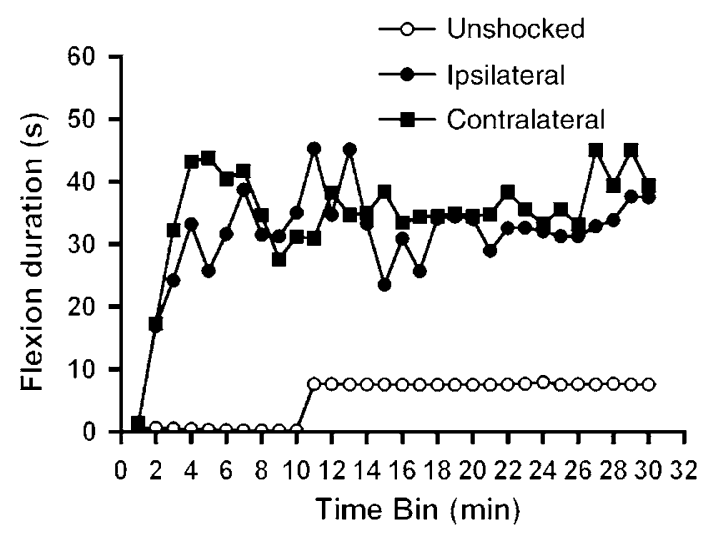

Figure 4 Prior training with controllable FES enables learning on the contralateral leg. Subjects trained with response-contingent electrical stimulation were able to learn when tested on the contralateral leg with a more difficult response criterion. Rats that were not pretrained (unshocked) could not learn this task

is enabled when they are tested on the opposite leg using a higher response criterion. ${ }^{11}$ Similarly, exposure to uncontrollable legshock (or tailshock) disables learning when subjects are tested on the opposite limb. ${ }^{10}$ The fact that these effects transfer to the contralateral limb implies that both depend on neurons within the spinal cord.

Additional evidence that spinal neurons play an important role comes from studies examining the impact of eliminating communication with the spinal cord by cutting the sciatic nerve. Severing the sciatic nerve eliminates the capacity for learning (Crown et al: ${ }^{11}$ Figure 5a). In addition, cutting the sciatic nerve before administering uncontrollable stimulation to the same leg blocks the induction of the deficit when subjects are subsequently tested on the contralateral leg. ${ }^{13}$

Pharmacological manipulations also implicate spinal neurons. If spinal neurons are anesthetized through the local (intrathecal) application of the $\mathrm{Na}^{+}$channel blocker lidocaine, subjects fail to learn (Crown et al ${ }^{11}$ Figure 5c). Similarly, intrathecal lidocaine before uncontrollable shock blocks the induction of the deficit observed when subjects are tested 24 h later. ${ }^{13}$

Neither lidocaine nor cutting the sciatic nerve eliminated the behavioral response (Crown et al: ${ }^{11}$ Joynes et al ${ }^{13}$ Figures $5 \mathrm{~b}$ and d). As generally assumed within FES paradigms, the electrical stimulation drives the motor response even though communication with the spinal cord has been disrupted - the stimulationinduced response does not reflect a spinally mediated withdrawal response. What spinal neurons appear to do in this procedure is (1) detect whether a responseoutcome relation exists, and (2) on the basis of this information, modulate the consequences of stimulation. In particular, when a response-outcome relation exists, spinal neurons can amplify the consequences of stimulation and thereby promote adaptive behavior. Using fluorescent tracing, selective knife cuts and 
a

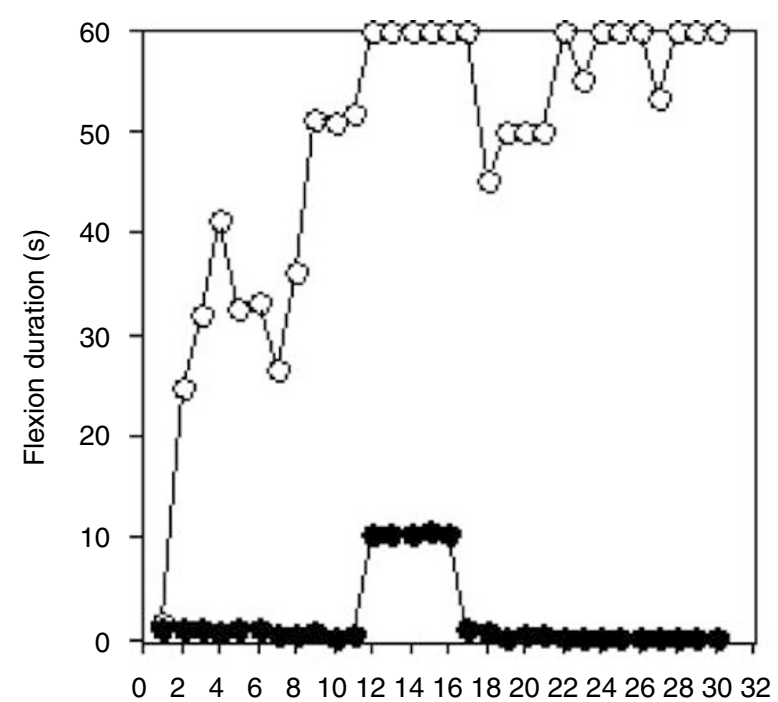

C

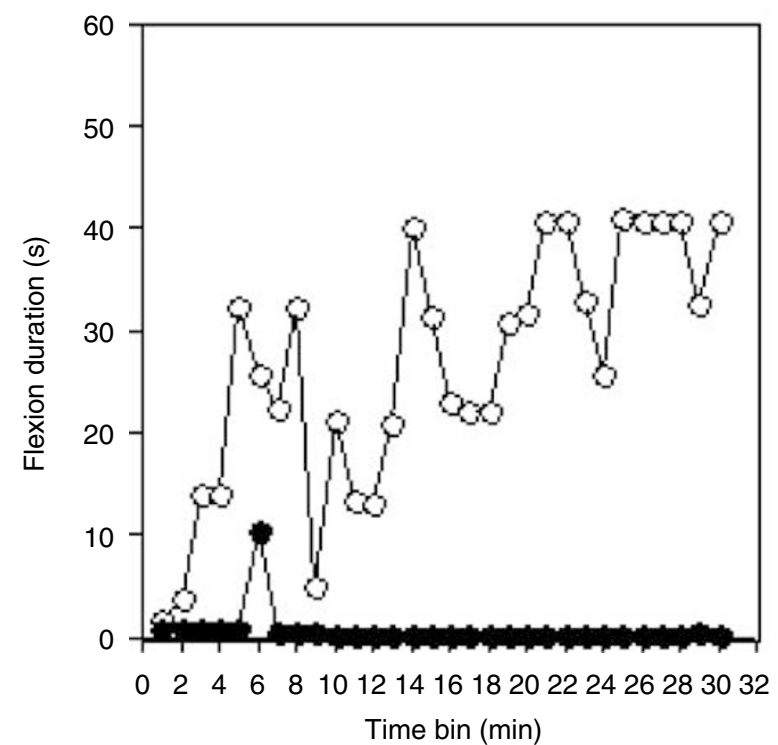

b

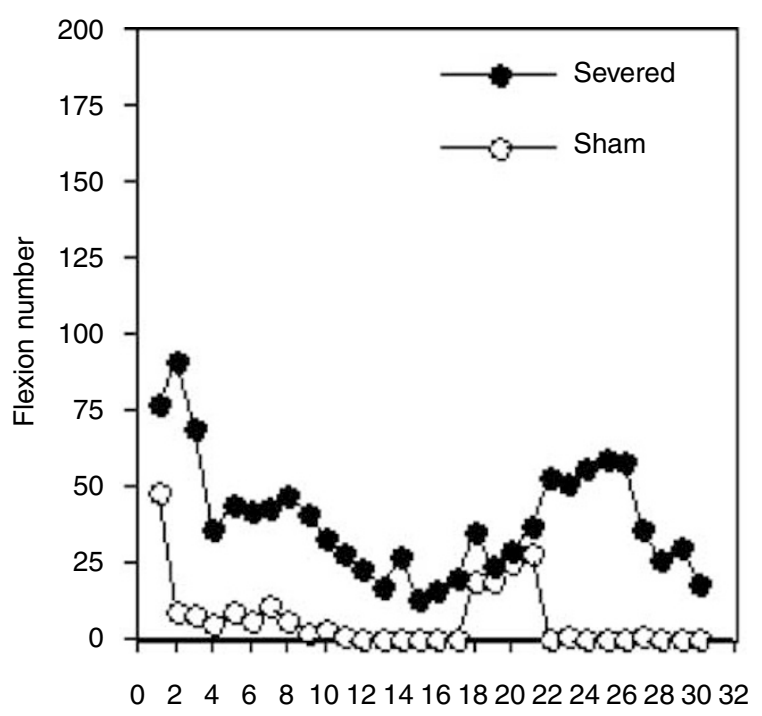

d

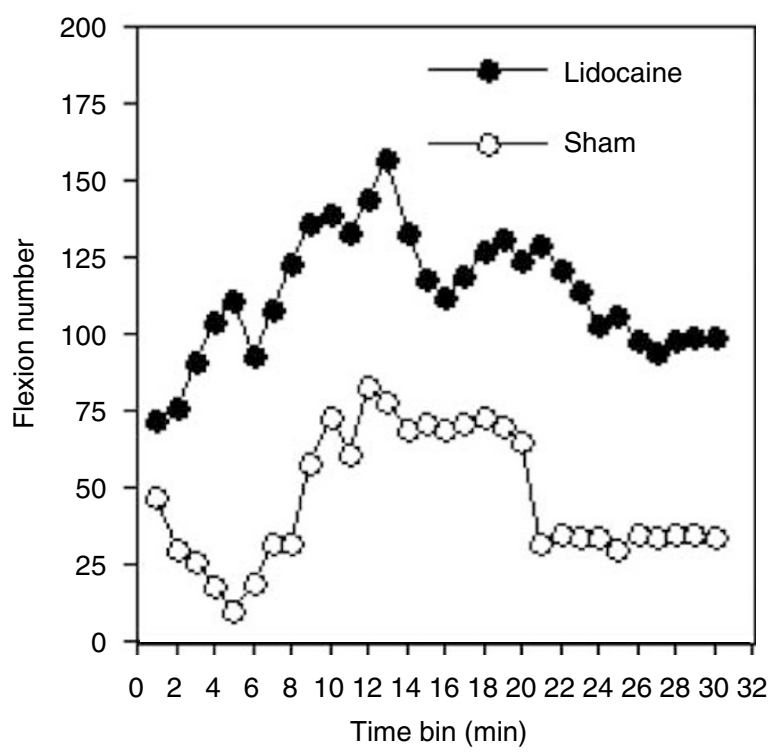

Figure 5 Spinal neurons contribute to FES-evoked changes in behavior. Cutting the sciatic nerve (a) or anesthetizing the cord with intrathecal lidocaine (c) eliminates the increase in flexion duration usually seen with response-contingent electrical stimulation. Neither manipulation eliminates the capacity to perform a flexion response (b and d, respectively). Adapted from Crown et $a l^{10}$

circumscribed application of lidocaine, we have shown that the neurons needed to encode the response-outcome relation lie within the L4-S2 region in our learning paradigm. ${ }^{14}$ This same region appears to contain the central pattern generator hypothesized to underlie coordinated stepping in spinally transected subjects. ${ }^{15}$ Interestingly, evidence suggests that this circuit too is capable of learning. If a spinally transected animal is trained to step on a treadmill, and an obstacle is placed in its path, so that the front surface of one paw hits the obstacle during the swing phase, subjects will learn to lift the leg higher to minimize contact with the obstacle. ${ }^{16}$

\section{Intermittent and continuous shocks have opposing effects}

The recognition that uncontrollable nociceptive stimulation can inhibit spinal plasticity led us to explore how this effect is related to other examples of nociceptive modulation and plasticity. One basic question is whether the induction of the deficit depends on pain $\mathrm{C}$ fibers. When strongly stimulated, unmyelinated afferent C fibers release the neurotransmitter substance $\mathrm{P}$ within the dorsal horn of the spinal cord. ${ }^{17}$ The release of substance $\mathrm{P}$ has been linked to both the psychological 
experience of burning pain and the induction of central sensitization. ${ }^{18}$ Kyle Baumbauer ${ }^{19}$ examined whether blocking the substance $\mathrm{P}$ (neurokinin) receptor through the intrathecal application of an antagonist affects the induction of the learning deficit. $\mathrm{He}$ found that pretreatment with an NK1 antagonist blocks the induction of the learning deficit, but does not impair instrumental learning. ${ }^{19}$ This suggests that the induction of the deficit depends on the activation of pain fibers.

In other studies, we have shown that exposure to an intense continuous shock can engage pain-inhibitory (antinociceptive) systems within the spinal cord. ${ }^{10,20}$ Using tailshock, we found that 15-360 s of continuous shock produced a strong antinociception as measured by tail withdrawal from radiant heat (the tail-flick test). ${ }^{10}$ Continuous stimulation did not, however, induce a learning deficit. In contrast, $360 \mathrm{~s}$ of intermittent shock produced a robust learning deficit but not antinociception. Rather than depressing behavioral reactivity, exposure to intermittent shock increased reactivity to mechanical stimulation (allodynia), a phenomenon that has been linked to the induction of central sensitization and the development of neuropathic pain. ${ }^{9,21}$

Continuous electrical stimulation through fixed skin electrodes is often used in clinical settings to induce a pain-inhibitory effect, a procedure known as transcutaneous electrical nerve stimulation (TENS). ${ }^{22}$ If intermittent shock impairs spinal plasticity, because it overexcites nociceptive systems, perhaps the induction of the opposite phenomenon (antinociception) would have a protective effect. Supporting this, Crown et al ${ }^{10}$ applied a continuous shock to the tail, whereas spinal rats received intermittent shock (180 80-ms shocks, presented approximately $2 \mathrm{~s}$ apart) to one hind leg. Subjects were then tested the next day with controllable shock applied to the opposite leg. Crown et al ${ }^{10}$ found that the concurrent application of continuous shock had a protective effect that blocked the induction of the learning deficit. This suggests that treatment with TENS could have a beneficial effect in situations where uncontrollable nociceptive stimulation cannot be avoided.

The fact that uncontrollable shock enhanced mechanical reactivity led us to explore whether other manipulations that induce allodynia affect spinal learning. Prior evidence indicates that intradermal capsaicin induces a peripheral inflammation that sensitizes spinal neurons and leads to allodynia. ${ }^{9}$ Intradermal capsaicin also induces a learning deficit. ${ }^{23}$ Moreover, pharmacological treatments that are known to block the induction of central sensitization also block the induction of the learning deficit. ${ }^{19,24-26}$ Given these observations, we have suggested that uncontrollable shock impairs subsequent learning, because it produces a form of overexcitation akin to central sensitization. ${ }^{23}$

\section{Learning is mediated by the NMDAR}

Our animal model of FES has allowed us to demonstrate that spinal neurons modulate the consequences of
FES. Furthermore, it enables the exploration of the neural mechanisms that mediate this effect. In the hippocampal literature, learning and memory have been linked to the release of glutamate and the activation of the $N$-methyl-D-aspartic acid receptor (NMDAR). ${ }^{27,28}$ Electrophysiological studies have shown that a strong depolarization can release the $\mathrm{Mg}^{2+}$ block from the NMDAR, allowing $\mathrm{Ca}^{2+}$ to flow into the postsynaptic cell. This engages intracellular signals, such as CaMKII, which can impact fast neural conduction through a modification of the $\alpha$-amino-3-hydroxy-5-methyl-4isoxazolepropionic acid receptor (AMPAR) ${ }^{29}$ Highfrequency stimulation leads to a form of long-term potentiation (LTP) that has been linked to the activation of AMPAR subunits and their trafficking (insertion) into the cell membrane, both of which enhance the response elicited in the postsynaptic cell. ${ }^{30}$ Conversely, low-frequency stimulation can induce a long-term depression (LTD) that has been tied to the inactivation of AMPARs and the deletion of AMPARs from the active region of the synapse. ${ }^{30}$ Recent studies have shown that both the NMDAR and AMPAR are widely distributed within the spinal cord and that spinal neurons can support LTP and LTD. ${ }^{31,32}$

Given these observations, we hypothesized that instrumental learning may depend on a form of NMDAR-mediated plasticity. Indeed, pretreatment with an NMDA antagonist (APV or MK-801; Figure 6) blocked instrumental learning. ${ }^{26,33}$ Learning is also blocked by the AMPAR antagonist 6-cyano-7-nitroquinoxaline-2,3-dione. ${ }^{34}$

Earlier we suggested that intermittent nociceptive stimulation may block learning, because it induces a diffuse overexcitation of spinal neurons akin to central sensitization. At a cellular level, we hypothesized that this might occur because stimulation saturates NMDAR-mediated plasticity. ${ }^{10,26}$ If this is true, pretreatment with an NMDAR antagonist should block the induction of the learning deficit observed when subjects are tested $24 \mathrm{~h}$ later, after the drug has cleared the system. As predicted, Ferguson et $a l^{26}$ found that pretreatment with MK-801 blocked the induction of the learning deficit.

The expression of the deficit also appears linked to the release of an opioid peptide. Supporting this, Joynes and $\mathrm{Grau}^{35}$ compared the impact of an opioid antagonist given before the initial exposure to intermittent shock or $24 \mathrm{~h}$ later, before testing. The antagonist had no effect when given before intermittent shock, but reversed the deficit when given before testing. Thus, the opioid antagonist blocked the expression, but not the induction, of the learning deficit. Subsequent studies have tied this effect to the $\kappa$-opioid receptor. ${ }^{36}$ Interestingly, other work suggests that engaging this receptor inhibits NMDAR-mediated plasticity. ${ }^{37}$

Learning also appears to impact the neurotrophin brain-derived neurotrophic growth factor (BDNF) ${ }^{38} \mathrm{In}$ collaboration with Gomez-Pinilla, we have shown that the instrumental training upregulates BDNF mRNA 

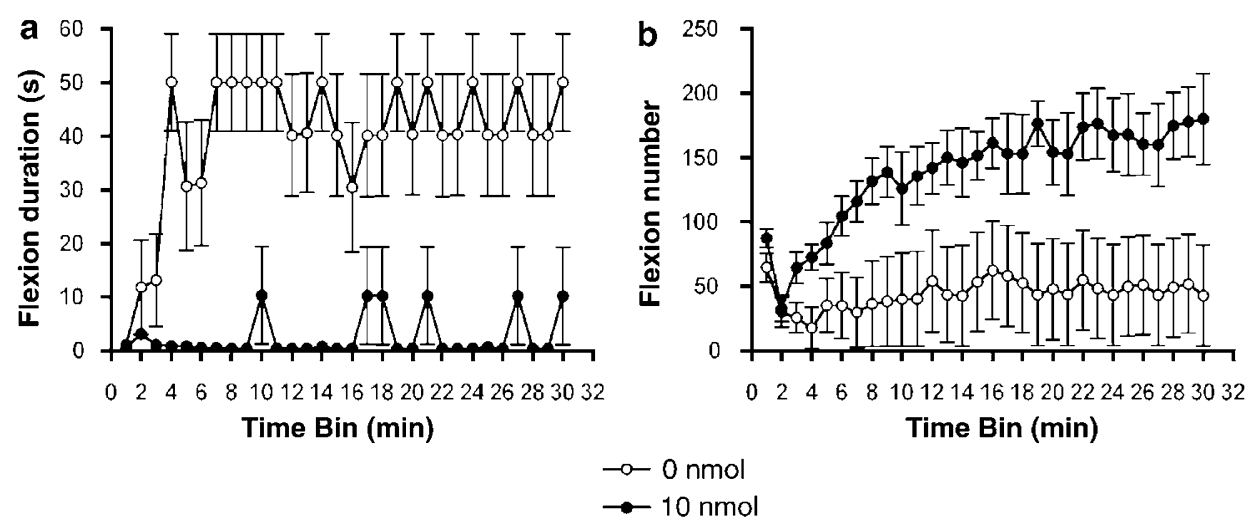

Figure 6 FES-evoked changes in flexion depend on NMDAR activity. (a) Intrathecal administration of an NMDAR antagonist (10 nmol MK-801) blocked the induction of learning (response duration), but not the shock-elicited motor response (b)

expression. As BDNF is known to foster NMDARmediated plasticity, ${ }^{39}$ we hypothesized that this ligand may contribute to the enabling of spinal plasticity. Tests showed that pretreatment with a BDNF inhibitor eliminated the enabling effect. ${ }^{40}$ Conversely, intrathecal application of BDNF before testing with a highresponse criterion enabled learning. ${ }^{41}$

These studies suggest that spinal learning depends on many of the same neurochemical systems implicated in other model paradigms. In addition, they suggest some attractive therapeutic targets. For example, we have shown that administration of an opioid antagonist can temporarily block the expression of the learning deficit. When this drug treatment is coupled with instrumental training, the deficit appears to be permanently erased. Similarly, the application of BDNF, which is known to foster synaptic plasticity, and enable learning, could enhance the behavioral consequences of FES training.

\section{Uncontrollable electrical stimulation undermines recovery after a contusion injury}

We have also extended the findings obtained using a transection model to a contusion paradigm. Male Sprague-Dawley rats are given a moderate contusion injury (12.5 mm drop) with the NYU impactor. ${ }^{42}$ Response-contingent (controllable) and uncontrollable electrical stimulation is applied in the same way as described for the transection model, $24 \mathrm{~h}$ after injury, and after a baseline assessment of locomotor function (Basso-Beattie-Bresnahan scale ${ }^{43}$ ). We have found that just $6 \mathrm{~min}$ of uncontrollable, but not controllable, electrical stimulation to the hind leg or tail disrupts the recovery of motor, sensory and bladder functions for up to 6 weeks after treatment (Grau et al ${ }^{44}$ Figure 7a).

The adverse consequences of uncontrollable electrical stimulation appear to diminish as the subject's recover. ${ }^{44}$ The greatest effect was observed 1-4 days after injury (Figure $7 \mathrm{~b}$ ). These data suggest that there may be some benefit to delaying the onset of rehabilitation treatments that involve nociceptive stimulation.

\section{Conclusions}

FES produces long-term changes in spinal neural circuitry and has the potential to, together with behavioral training, benefit recovery of function after a spinal injury. The capacity for reshaping the neural circuitry of the spinal system to support long-term functional recovery is further substantiated by reports of therapeutic benefits of FES training even when electrical stimulation is turned off. ${ }^{2,46}$ As the studies reviewed here demonstrate, many of the changes induced with electrical stimulation may be mediated by spinal circuitry.

Our studies have shown that the spinal cord is inherently capable of adapting to environmental events, including electrical stimulation, and is sensitive to the temporal relationships between stimuli. In particular, spinal neurons seem to learn punishment relations. Others have also shown that spinal neurons can, in the absence of supraspinal input, alter pain processing (see, eg, Schouenborg et $a l^{47}$ ), influence drug reactivity, ${ }^{48}$ organize locomotor behavior ${ }^{49}$ and adapt to new stimulus-stimulus (Pavlovian conditioning ${ }^{50,51}$ ) relations. Traditionally, the spinal cord has been viewed as a simple conduit for information traveling to and from the brain. Clearly, this is not the case.

In our studies, the spinal cord learned the relationship between a specific leg position and electrical stimulation of the tibialis anterior muscle. This is similar to the clinical procedure used to correct footdrop and to facilitate the swing phase of the locomotor cycle during gait rehabilitation. The commercially available Parastep (Sigmedics Inc., Fairborn, OH, USA), for example, incorporates stimulation of the common peroneal nerve to elicit flexion during the swing phase of the gait cycle. This type of training is associated with improvements in functional walking ability, muscle strength and coordination, $2,52-54$ and is significantly effective even in chronic spinal cord injury patients. One criticism of this rehabilitative technique, however, is that it is highly variable and subject to rapid habituation. ${ }^{55}$ Interestingly, in our studies, we have not observed 

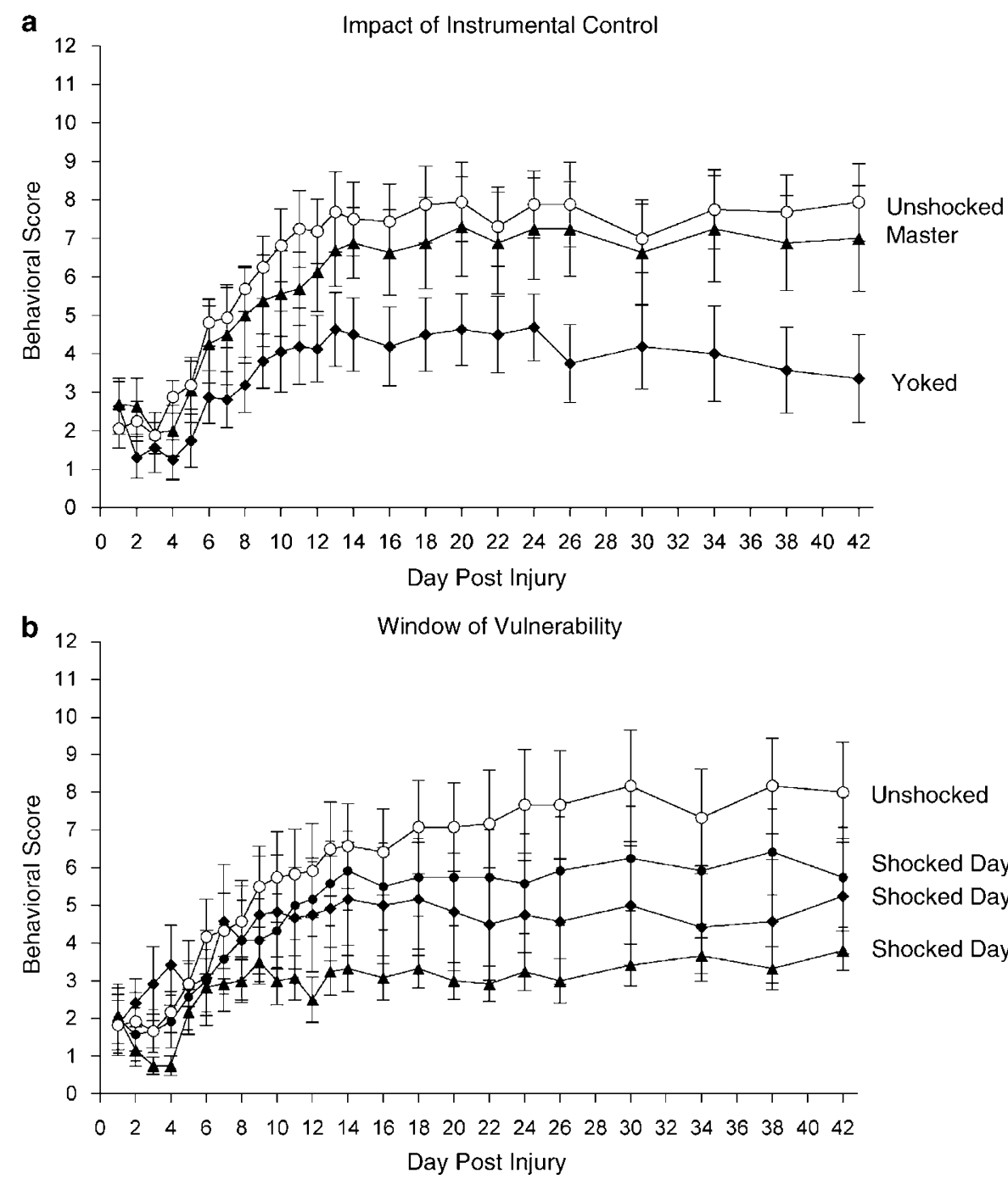

Unshocked

Shocked Day 14

Shocked Day 4

Shocked Day 1

Figure 7 Effects of response-contingent and uncontrollable FES training on the recovery of function. Locomotor recovery was assessed using a modified version of the scale developed by Basso et al. ${ }^{43}$ The modification ${ }^{45}$ improves the metric properties of the scale and increases statistical power. Rats received training with response-contingent electrical stimulation (master), uncontrollable stimulation (yoked) or nothing (unshocked) 24 and $48 \mathrm{~h}$ after injury. Only uncontrollable stimulation disrupted recovery (a). Uncontrollable stimulation was given 1, 4 or 14 days after injury. Delaying uncontrollable stimulation reduced its adverse effect on recovery (b). Adapted from Grau et al. ${ }^{44}$

habituation of the target flexion response when the subjects have 'control' over the stimulation paradigm. Habituation is observed when we eliminate communication with the spinal cord (sever sciatic nerve) or present uncontrollable electrical stimulation. In these circumstances, the stimulation elicits the target response but, without the benefit provided by adaptive systems within the spinal cord, there is a gradual decline in response strength. Conversely, with a predictable, controllable stimulation paradigm, the spinal system adjusts behavior to minimize exposure to the electrical stimulus, which facilitates the performance of the target response (leg flexion). Habituation in the clinical setting may be due to a lack of 'controllability' in the stimulation protocol. Further, our work suggests that the long-term clinical effectiveness of alternative FES procedures may depend, in part, upon the extent to which they utilize response-contingent stimulation that enlists the helping hand of spinal neurons to promote adaptive behavior. Interestingly, commercially available footdrop systems (The Footlifter, Elmetec A/S, Arhus, Denmark; Walkaide, Hanger Orthopedic Group Inc., Bethesda, MD, USA; The Odstock Footdrop Stimulator, Odstock Medical Ltd, Salisbury, UK; Actigait, Neurodan A/S, Aalborg, Denmark; Finetech Dropped Foot System, Finetech Medical Ltd, UK) do depend on distinct responses (heel switch or built-in tilt sensors) to trigger the onset of electrical stimulation. In these paradigms, electrical stimulation is controllable and, we would argue, this contributes to their clinical effectiveness.

Although it would be misleading to claim that our model applies to all forms of FES, we suggest that the 
basic principles may be relevant to other therapeutic FES paradigms; feedback from proprioceptors in the muscles (tendons and joints) will provide afferent input to the spinal cord, and may lead to the modification of plastic reflex circuits. Indeed, electrical stimulation may provide a way to reshape remaining neural circuits after injury and thereby restore more naturalistic functional behavior. Our data also suggest that recovery may be further facilitated by (1) linking stimulation to a specific functional response, and (2) allowing the 'spinal cord' to minimize exposure to electrical stimulation. For example, a locomotor system that signals the impending electrical stimulation (at a precise joint position) and provides an opportunity to avoid electrical stimulation, by performing an appropriate response during the signal, may further help recovery. This type of system would provide an opportunity for the spinal cord to learn, and would be analogous to the stimulation protocol described in Figure 1d.

An understanding of the capacity of FES training to shape neural circuits will be an important component for facilitating recovery of function after a spinal cord injury. As researchers delineate the conditions needed to promote regeneration of spinal neurons, and therapies to attenuate tissue loss, methods that facilitate appropriate patterns of connectivity between neural circuits will be integral. Maladaptive sensory connections may lead to chronic pain ${ }^{56}$ or the emergence of interlimb reflexes that provide no functional benefit to the subject. $^{57}$ FES training regimens could be used to encourage appropriate adaptive patterns of neural activity that support the recovery of function.

\section{Acknowledgements}

This research was funded by NINDS Grants NS41548 and NS051443, and NIDA grant DA020596.

\section{Statement of ethics}

We certify that all applicable institutional and governmental regulations concerning the ethical use of animals were followed during the course of this research.

\section{References}

1 Creasey $\mathrm{GH}$ et al. Clinical applications of electrical stimulation after spinal cord injury. J Spinal Cord Med 2004; 27: 365-375.

2 Barbeau H, Ladouceur M, Mirbagheri MM, Kearney RE. The effect of locomotor training combined with functional electrical stimulation in chronic spinal cord injured subjects: walking and reflex studies. Brain Res Brain Res Rev 2002; 40: 274-291.

3 Grau JW, Barstow DG, Joynes RL. Instrumental learning within the spinal cord: I. Behavioral properties. Behav Neurosci 1998; 112: 1366-1386.

4 Hoffer JA et al. Neural signals for command control and feedback in functional neuromuscular stimulation: a review. J Rehabil Res Dev 1996; 33: 145-157.

5 Maier SF, Seligman MEP. Learned helplessness: theory and evidence. J Exp Psychol Gen 1976; 105: 3-46.
6 Grau JW, Crown ED, Ferguson AR, Washburn SN, Hook MA, Miranda RC. Instrumental learning within the spinal cord: underlying mechanisms and implications for recovery after injury. Behav Cogn Neuro Rev 2006; 5: 191-239.

7 Peckham PH, Knutson JS. Functional electrical stimulation for neuromuscular applications. Annu Rev Biomed Eng 2005; 7: 327-360.

8 Young EE, Baumbauer KM, Elliot A, Joynes RL. The impact of neonatal injury on spinally mediated instrumental learning in adult rats. Behav Neurosci 2007 (in press).

9 Willis WD. Long-term potentiation in spinothalamic neurons. Brain Res Brain Res Rev 2002; 40: 202-214.

10 Crown ED, Ferguson AR, Joynes RL, Grau JW. Instrumental learning within the spinal cord: IV. Induction and retention of the behavioral deficit observed after noncontingent shock. Behav Neurosci 2002b; 116: 1032-1051.

11 Crown ED, Ferguson AR, Joynes RL, Grau JW. Instrumental learning within the spinal cord. II. Evidence for central mediation. Physiol Behav 2002a; 77: 259-267.

12 Crown ED, Grau JW. Preserving and restoring behavioral potential within the spinal cord using an instrumental training paradigm. $J$ Neurophysiol 2001; 86: 845-855.

13 Joynes RL, Ferguson AR, Crown ED, Patton BC, Grau JW. Instrumental learning within the spinal cord: V. Evidence the behavioral deficit observed after noncontingent nociceptive stimulation reflects an intraspinal modification. Behav Brain Res 2003; 141: 159-170.

14 Liu GT, Ferguson AR, Crown ED, Bopp AC, Miranda RC, Grau JW. Instrumental learning within the rat spinal cord: localization of the essential neural circuit. Behav Neurosci 2005; 119: 538-547.

15 Rossignol S, Bouyer L, Barthelemy D, Langlet C, Leblond H. Recovery of locomotion in the cat following spinal cord lesions. Brain Res Brain Res Rev 2002; 40: 257-266.

16 Edgerton VR, Tillakaratne NJK, Bigbee AJ, de Leon RD, Roy RR. Plasticity of the spinal neural circuitry after injury. Annu Rev Neurosci 2004; 27: 145-167.

17 Lang CW, Hope PJ. Evidence for localized release of substance $\mathrm{P}$ within rat spinal cord evoked by physiological and electrical stimuli. Neuropeptides 1994; 26: 413-419.

18 Willis WD. Role of neurotransmitters in sensitization of pain responses. Ann NY Acad Sci 2001; 933: 142-156.

19 Baumbauer KM, Hoy KC, Young EE, Joynes RL. Intrathecal administration of the NK1 receptor antagonist L-703,606 undermines the savings effect and reverses the learning deficit observed in spinally mediated instrumental learning.Program No. 396.20. In 2005 Abstract Viewer/ Itinerary Planner. Society for Neuroscience: Washington, DC, 2005.

20 Meagher MW, Chen PS, Salinas JA, Grau JW. Activation of the opioid and nonopioid hypoalgesic systems at the level of the brainstem and spinal cord: does a coulometric relation predict the emergence or form of environmentally induced hypoalgesia? Behav Neurosci 1993; 107: 493-505.

21 Woolf CJ, Wall PD. Relative effectiveness of C primary afferent fibers of different origins in evoking a prolonged facilitation of the flexor reflex in the rat. J Neurosci 1986; 6: 1433-1442.

22 Ainsworth L et al. Transcutaneous electrical nerve stimulation (TENS) reduces chronic hyperalgesia induced by muscle inflammation. Pain 2006; 120: 182-187.

23 Hook MA, Huie JR, Grau JW. Instrumental learning in spinalized rats: the induction of central sensitization undermines behavioral plasticity in the spinal cord. Program No. 783.12. 2005. Abstract Viewer/Itinerary 
Planner. Society for Neuroscience: Washington, DC.CDROM. 2005.

24 Ferguson AR, Washburn SN, Crown ED, Grau JW. GABA-A activation is involved in noncontingent shock inhibition of instrumental conditioning in spinal rats. Behav Neurosci 2003; 117: 799-812.

25 Bolding KA, Ferguson AR, Hook MA, Grau JW. The protein kinase $\mathrm{C}$ inhibitor, bisindolylmaleimide-I, dosedependently prevents a shock-induced behavioral deficit in spinalized rats.Program No. 497.2. 2003. Abstract Viewer/ Itinerary Planner. Society for Neuroscience: Washington, DC.CD-ROM. 2003.

26 Ferguson AR, Crown ED, Grau JW. Nociceptive plasticity inhibits adaptive learning in the spinal cord. Neuroscience 2006; 141: 421-431.

27 Fanselow MS, Kim JJ, Yipp J, De Oca B. Differential effects of the $N$-methyl-D-aspartate antagonist DL-2amino-5-phosphonovalerate on acquisition of fear of auditory and contextual cues. Behav Neurosci 1994; 108: 235-240.

28 Kishimoto Y, Nakazawa K, Tonegawa S, Kirino Y, Kano M. Hippocampal CA3 NMDA receptors are crucial for adaptive timing of trace eyeblink conditioned response. J Neurosci 2006; 26: 1562-1570.

29 Lee HK, Barbarosie M, Kameyama K, Bear MF, Huganir RL. Regulation of distinct AMPA receptor phosphorylation sites during bidirectional synaptic plasticity. Nature 2000; 405: 955-959.

30 Malenka RC. Synaptic plasticity and AMPA receptor trafficking. Ann NY Acad Sci 2003; 1003: 1-11.

31 Sandkuhler J, Chen JG, Cheng G, Randic M. Lowfrequency stimulation of afferent Adelta-fibers induces long-term depression at primary afferent synapses with substantia gelatinosa neurons in the rat. J Neurosci 1997; 17: 6483-6491.

32 Sandkuhler J, Liu X. Induction of long-term potentiation at spinal synapses by noxious stimulation or nerve injury. Eur J Neurosci 1998; 10: 2476-2480.

33 Joynes RL, Janjua K, Grau JW. Instrumental learning within the spinal cord: VI. The NMDA receptor antagonist, AP5, disrupts the acquisition and maintenance of an acquired flexion response. Behav Brain Res 2004; 154: 431-438.

34 Hoy KC, Huie JR, Grau JW. Administration of the AMPA antagonist CNQX disrupts instrumental learning, and the induction of a learning deficit, in spinally transected rats.2006 Abstract Viewer/Itinerary Planner. Society for Neuroscience: Washington, DC, 2006.

35 Joynes RL, Grau JW. Instrumental learning within the spinal cord: III. Prior exposure to noncontingent shock induces a behavioral deficit that is blocked by an opioid antagonist. Neurobiol Learn Mem 2004; 82: $35-51$.

36 Washburn SN, Maultsby ML, Grau JW. The K2 opioid receptor agonist GR89696 has both adverse and beneficial effects on spinal cord plasticity.Program No. 396.19. 2005 Abstract Viewer/Itinerary Planner. Society for Neuroscience: Washington, DC, 2005.

37 Caudle RM, Chavkin C, Dubner R. Kappa 2 opioid receptors inhibit NMDA receptor-mediated synaptic currents in guinea pig CA3 pyramidal cells. J Neurosci 1994; 14: $5580-5589$

38 Gómez-Pinilla F, Ying Z, Ferguson A, Crown E, Edgerton VR, Grau JW. BDNF supports spinal cord learning.Abstract Viewer/Itinerary Planner. Society for Neuroscience: Washington, DC.CD-ROM. 2004.
39 Garraway SM, Petruska JC, Mendell LM. BDNF sensitizes the response of lamina II neurons to high threshold primary afferent inputs. Eur J Neurosci 2003; 18: 2467-2476.

40 Huie JR, Gomez-Pinilla F, Ying Z, Edgerton VR, Grau JW. BDNF enables learning in the rat spinal cord.Program No. 175.16. In 2005 Abstract Viewer/Itinerary Planner. Society for Neuroscience: Washington, DC, 2005.

41 Huie JR, Hoy Jr KC, Miranda R, Grau JW. BDNF facilitates learning in the rat spinal cord.Abstract Viewer/ Itinerary Planner. Society for Neuroscience: Washington, DC.CD-ROM. 2006.

42 Gruner JA. A monitored contusion model of spinal cord injury in the rat. J Neurotrauma 1992; 9: 123-126; discussion $126-128$.

43 Basso DM, Beattie MS, Bresnahan JC. A sensitive and reliable locomotor rating scale for open field testing in rats. $J$ Neurotrauma 1995; 12: 1-21.

44 Grau JW et al. Uncontrollable stimulation undermines recovery after spinal cord injury. $J$ Neurotrauma 2004; 21 : 1795-1817.

45 Ferguson AR, Hook MA, Garcia G, Bresnahan JC, Beattie MS, Grau JW. A simple post hoc transformation that improves the metric properties of the BBB scale for rats with moderate to severe spinal cord injury. $J$ Neurotrauma 2004; 21: 1601-1613.

46 Barbeau H, Ladouceur M, Norman KE, Pepin A, Leroux A. Walking after spinal cord injury: evaluation, treatment, and functional recovery. Arch Phys Med Rehabil 1999; 80: 225-235.

47 Schouenborg J, Holmberg H, Weng HR. Functional organization of the nociceptive withdrawal reflexes. II. Changes of excitability and receptive fields after spinalization in the rat. Exp Brain Res 1992; 90: 469-478.

48 Mao J, Mayer DJ. Spinal cord neuroplasticity following repeated opioid exposure and its relation to pathological pain. Ann NY Acad Sci 2001; 933: 175-184.

49 Pearson KG, Rossignol S. Fictive motor patterns in chronic spinal cats. J Neurophysiol 1991; 66: 1874-1887.

50 Illich PA, Salinas JA, Grau JW. Latent inhibition, overshadowing, and blocking of a conditioned antinociceptive response in spinalized rats. Behav Neural Biol 1994; 62: 140-150.

51 Joynes RL, Grau JW. Mechanisms of Pavlovian conditioning: role of protection from habituation in spinal conditioning. Behav Neurosci 1996; 110: 1375-1387.

52 Ladouceur M, Barbeau H. Functional electrical stimulation-assisted walking for persons with incomplete spinal injuries: changes in the kinematics and physiological cost of overground walking. Scand J Rehabil Med 2000; 32: 72-79.

53 Field-Fote EC. Combined use of body weight support, functional electric stimulation, and treadmill training to improve walking ability in individuals with chronic incomplete spinal cord injury. Arch Phys Med Rehabil 2001; 82: 818-824.

54 Field-Fote EC, Tepavac D. Improved intralimb coordination in people with incomplete spinal cord injury following training with body weight support and electrical stimulation. Phys Ther 2002; 82: 707-715.

55 Thrasher TA, Flett HM, Popovic MR. Gait training regimen for incomplete spinal cord injury using functional electrical stimulation. Spinal Cord 2006; 44: 357-361.

56 Christensen MD, Hulsebosch CE. Chronic central pain after spinal cord injury. J Neurotrauma 1997; 14: 517-537.

57 Calancie B, Alexeeva N, Broton JG, Molano MR. Interlimb reflex activity after spinal cord injury in man: strengthening response patterns are consistent with ongoing synaptic plasticity. Clin Neurophysiol 2005; 116: 75-86. 